\title{
Awareness among Patients regarding Dental Implants as a Treatment Option for replacing Missing Teeth in Melmaruvathur Population
}

\author{
${ }^{1}$ Venkatesan Narayanan, ${ }^{2}$ Prabhu Karuppiah, ${ }^{3}$ Arunkumar Rajasekar, ${ }^{4}$ Lakshmi D Mayavan
}

\begin{abstract}
Background: Treatment with dental implants has become increasingly important in the range of prosthodontic treatment. Significant improvements in oral rehabilitation particularly in edentulous individuals have been seen. In Adhiparasakthi Dental College, Melmaruvathur, a survey was made to evaluate awareness among patients for dental implants, their level of knowledge, and attitude toward replacement of missing teeth by dental implants.

Materials and methods: A survey of 480 people was conducted through a printed questionnaire and completed by willing respondents. The questionnaires were prepared in English and Tamil language to enable better understanding and completion.

Results: Of the 510 people surveyed, 480 responses were retrieved, of which 331 were aware of dental implant treatment in Melmaruvathur, Tamil Nadu. Among them, 304 respondents were aware that implants could be used for replacement of missing teeth. Most of the respondents stated that dental implants were placed in the jawbone, followed by gums. Only $41 \%$ respondents assumed that implants last for a lifetime and only $35 \%$ of respondents believe that poor oral hygiene was the most common cause of implant failure.
\end{abstract}

Conclusion: More dental education programs are needed to improve understanding of the importance of restoration of missing teeth. General implant awareness levels are satisfactory. However, increased awareness of patients for restoration of missing tooth with dental implants is necessary. Dental education programs with special emphasis on advantages, treatment, maintenance, and postoperative care of dental implant therapy are needed. More than two-thirds of the surveyed population is interested in knowing about and being treated with dental implants.

Keywords: Awareness, Dental implants, Melmaruvathur, Survey, Treatment.

How to cite this article: Narayanan V, Karuppiah P, Rajasekar A, Mayavan LD. Awareness among Patients regarding Dental Implants as a Treatment Option for replacing Missing Teeth in Melmaruvathur Population. Int J Prosthodont Restor Dent 2016;6(1):6-9.

Source of support: Nil

Conflict of interest: None

\footnotetext{
${ }^{1}$ Professor, ${ }^{2}$ Reader, ${ }^{3,4}$ Senior Lecturer

${ }^{1-4}$ Department of Prosthodontics and Implantology, Adhiparasakthi Dental College and Hospital, Melmaruvathur, Tamil Nadu, India

Corresponding Author: Venkatesan Narayanan, Professor Department of Prosthodontics and Implantology, Adhiparasakthi Dental College and Hospital, Melmaruvathur, Tamil Nadu, India Phone: +919444144303, e-mail: naravenky@yahoo.com
}

\section{INTRODUCTION}

The aim of today's dentistry is to restore the patient to normal function, speech, esthetics, and health. Dental implants were originally used for treatment of edentulous patients and are associated with improved denture retention, stability, and functional efficiency. Due to the high success rates and predictability of dental implants, their prevalence in the rehabilitation of partially dentate and edentulous patients is increasing year by year. Advantages of implant-supported restorations include psychological benefits and tooth structure conservation adjacent to the teeth to be replaced. The overall desire for better oral health-related quality of life has become a reality in prosthetic dentistry. ${ }^{1}$

According to Pommer et $\mathrm{al}^{2}$ in Austria, there was, over the course of 5 years, a dramatic escalation in interest of implant treatment. At the time of the second survey (2008), 79\% of participants expressed desire for implant treatment in comparison with $56 \%$ in the first survey (2003).

The number of dental implants inserted annually worldwide has been estimated to be close to 1 million. However, the level of information available to patients about realistic, evidence-based treatment options with implants is often only fragmentary, and what is disseminated by the media and industry does not always reflect evidence-based data. ${ }^{3-5}$

For professionals, it is vital to assess a patient's level of knowledge with regard to dental implants and whether their perception of dental implants does in fact reflect reality, thus, alleviating the negative image of implant dentists due to miscommunication and patient discontent.

A questionnaire survey from a representative sample of the general Melmaruvathur population is therefore needed to assess public awareness and understanding of dental implants.

\section{AIMS AND OBJECTIVES}

- To evaluate the awareness among patients for dental implant therapy.

- To evaluate the level of knowledge among the populations with regard to dental implants therapy. 


\section{MATERIALS AND METHODS}

A questionnaire-based survey was conducted. All the respondents were informed about the aims and objectives of the study. Those who were not willing to participate were excluded from the study.

The demographic data of each patient including gender, age, education, and qualification were recorded before the survey.

The questionnaire with a total number of 18 questions for the survey was listed in numbers in the following order, of which the question numbers $1,4,5,6,7,9,10$, 11,12 were used for this study.

The survey study was conducted through printed self-explanatory questionnaire composed of questions with the intention of evaluating dental implant as a treatment option among the Melmaruvathur population. It consisted of 18 questions to find out the level of awareness and evaluating the level of information about dental implants. The questionnaire was prepared in both English and Tamil (local language) to enable completion and to improve the respondents' understanding of the questions. ${ }^{6-11}$

A total of 510 questionnaires were distributed to various age groups ranging from 20 years and younger, 21 to 40 years, 41 to 60 years, 61 to 80 years, and 80 years; of which, 480 were answered. They were also grouped according to various levels stated in the questionnaire.

\section{RESULTS}

The present survey gives information about patient's awareness, acceptance of dental implants as a treatment modality for replacement of missing teeth in dental patients in Melmaruvathur, Tamil Nadu, India. This study population (aged $<20-80$ years) was selected for ease of access and to increase the response rate, as they were dental patients who approached Adhiparasakthi Dental College and Hospitals for their treatment. In all, 480 patients participated in the survey $(\mathrm{M}=261(54 \%)$; $\mathrm{F}=219(48.14 \%)$. Table 1 summarizes the demographic data and Table 2 summarizes the survey data of the participating patients.

\section{General Awareness regarding replacing Missing Teeth}

For the question on whether missing teeth should be replaced, overall 38\% (182) were of the opinion that it was imperative to go for replacement of missing teeth in all cases, $36 \%$ (176) thought it was required only if it is aesthetically unpleasant, and $21 \%$ (105) reported it was not necessary to replace missing teeth. A majority of surveyed population seemed to understand the need for replacement of missing teeth.
Table 1: Demographic data

\begin{tabular}{lll}
\hline Demographic datas $^{3}$ & Total participants - 480 \\
\hline Gender & Male & $261(54 \%)$ \\
& Female & $219(46 \%)$ \\
Age (in years) & 20 and<20 years & $65(14 \%)$ \\
& $21-40$ & $207(43 \%)$ \\
& $41-60$ & $146(30 \%)$ \\
Education & $61-80$ & $62(13 \%)$ \\
& Up to high school level & $136(28 \%)$ \\
& Up to college & $190(40 \%)$ \\
& Up to university and above & $109(23 \%)$ \\
Qualification & Uneducated & $45(9 \%)$ \\
& Student & $66(14 \%)$ \\
& Unemployed & $56(12 \%)$ \\
& Housewife & $67(14 \%)$ \\
& Unskilled & $62(13 \%)$ \\
& Professional & $113(23 \%)$ \\
& Business & $116(24 \%)$ \\
\hline
\end{tabular}

\section{General Awareness Information about Dental Implants}

Majority of patients $(69 \% ; 331)$ had reported that they have heard of implant treatment before and only $26 \%$ (149) had reported that they had never heard about dental implants. Of the patients who had heard of implant treatment before, $42 \%$ (203) also stated that the dental implants will be placed in the jawbone and $58 \%$ (277) of the patients were totally unaware of where the implants will be placed.

A total of $32 \%$ (155) of patients felt they have poor awareness, 28\% (133) have moderate awareness, 35\% (169) have good awareness regarding dental implant therapy.

\section{Dental Implant as an Option for Replacement of Missing Teeth}

A total of $58 \%$ (280) of the patients were aware and $42 \%$ (200) were not aware that dental implants can be used to replace missing teeth.

\section{Life Span of Dental Implant Treatment}

As many as $24 \%$ (115) of patients thought dental implants would last up to 20 years, while majority of $41 \%$ (196) expected it to last for a lifetime.

\section{Need for Special Care and Hygiene}

While 54\% (263) felt dental implants needed less care in comparison to natural teeth and $46 \%$ (217) did feel that they require more care than the natural teeth.

\section{Interested in Knowing and Getting Treated with Dental Implants}

An overwhelming 75\% (362) of patients were willing to know and a $25 \%$ (118) of the patients were not interested to know about dental implant therapy. 
Table 2: Survey data

\begin{tabular}{|c|c|c|}
\hline \multirow{2}{*}{$\frac{\text { Sl. no. }}{1}$} & \multicolumn{2}{|l|}{ Survey data } \\
\hline & \multicolumn{2}{|c|}{ Do you know missing teeth should be replaced? } \\
\hline & (a) Yes, always & 227 \\
\hline & (b) Yes, if the gap is visible & 178 \\
\hline & (c) No, not necessary & 105 \\
\hline \multirow[t]{5}{*}{2} & \multicolumn{2}{|c|}{ What alternatives for replacing teeth do you know? } \\
\hline & (a) FPD & 167 \\
\hline & (b) RPD & 106 \\
\hline & (c) $\mathrm{CD}$ & 167 \\
\hline & (d) Implant & 70 \\
\hline \multirow[t]{3}{*}{3} & \multicolumn{2}{|c|}{$\begin{array}{l}\text { Would you be content with removable placement/ } \\
\text { denture as replacement for missing tooth? }\end{array}$} \\
\hline & (a) Yes & 262 \\
\hline & (b) No & 248 \\
\hline \multirow[t]{3}{*}{4} & \multicolumn{2}{|c|}{ Have you heard of implant treatment? } \\
\hline & (a) Yes & 357 \\
\hline & (b) No & 153 \\
\hline \multirow[t]{3}{*}{5} & \multicolumn{2}{|c|}{$\begin{array}{l}\text { Do you know that implants can be used for replaceme } \\
\text { of missing teeth? }\end{array}$} \\
\hline & (a) Yes & 304 \\
\hline & (b) No & 206 \\
\hline \multirow[t]{6}{*}{6} & \multicolumn{2}{|c|}{ How well informed do you feel about implant? } \\
\hline & (a) Very well & 41 \\
\hline & (b) Well & 114 \\
\hline & (c) Moderately well & 142 \\
\hline & (d) Poorly & 203 \\
\hline & (e) Not at all & 10 \\
\hline
\end{tabular}

$7 \quad$ Would you like to get implant treatment if needed?
(a) Yes
(b) Not at all

$8 \quad$ What do you personally think of dental implant treatment?
(a) Opted if needed
371
(b) Opted for other alternatives
139

9 Do you think Implant needs special care and hygiene?

(a) No 192

(b) No, less than natural teeth

(c) Yes, need more care

Like to know more about dental implants?

SI. no. Survey data

11 Where do you think dental implants are placed?

$\begin{array}{ll}\text { (a) Jaw bone } & 332 \\ \text { (b) Gums } & 63 \\ \text { c) Neighboring teeth } & 48 \\ \text { d) Do not know } & 67\end{array}$

12 How long do you think a dental implant lasts?
(a) $<5$ years
(b) $<10$
(c) Up to 20
(d) Life time
51

Biggest advantage of implant
(a) Fixed replacement 141
(b) Looks better 242
(c) Good in function 91

(d) Avoids grinding of natural teeth 36

Biggest disadvantage
(a) High cost
(b) Need of surgery
(c) Long treatment time

15 Reason for failure of dental implants
(a) Dentist
(b) Patient
(c) Poor oral hygiene
(d) Allergic/Incompatibility

16 What do you think of the treatment charges involved in this procedure?
(a) Affordable
176
(b) Non affordable
334

17 What in your opinion majorly contributes to the cost of dental implants?
(a) Cost of dental implants
277
(b) Cost of surgery
(c) Company supplying implant
(d) Dentist

18 Who in your opinion should opt for dental implant?
(a) Yes
(b) No

(a) Implants are good for every one

239

(b) Expensive only for rich

271

Of the patients willing to know about dental implant therapy, $74 \%$ (356) of patients were willing and 32\% (154) were not willing to get treated with implants.

\section{DISCUSSION}

Dental implant treatment has been at the forefront of clinical dental practice for over a decade and a half now. ${ }^{2}$ With increasing success rate of implant treatment, more patients are opting for dental implants as premier choice for replacement of missing teeth. Rising awareness of an advanced treatment modality in the society paves the way for its acceptability. However, advanced dental facilities are not in equal offering in all areas. At a time when metros and first-tier cities boast of latest advancement and technology, same is not true for the second-tier cities and rural areas. ${ }^{2}$
Surveys conducted to assess awareness level in patient population always come handy in deciding future approach. Although many surveys have been conducted on dental awareness there exist limited data on the patient awareness about dental implants in India, especially in Tamil Nadu.

Our survey reports conducted in Melmaruvathur, Kancheepuram district, Tamil Nadu, India, stated the following:

\section{General Awareness regarding Replacement of Missing Teeth}

About $60 \%$ of the people have stated that the missing teeth should be replaced, especially if it is unaesthetic. Thirty percent of the surveyed population had no 
awareness of the consequences of nonreplacement of the missing teeth.

\section{General Awareness Information about Implants}

An awareness level of "what is an Implant?" in Melmaruvathur population is about $69 \%$, which is not totally in contrast to one of the earliest surveys conducted on this topic by Zimmer et $\mathrm{al}^{3}$, which investigated the public awareness and acceptance of dental implants in 120 American citizens and reported awareness as high as $77 \%$. A recent study conducted in 1,000 Austrian individuals by Pommel et $\mathrm{al}^{2}$ also reports awareness of dental implants of $79 \%$, while a Norwegian survey ${ }^{6}$ reported in 2001 reported dental awareness level of $70 \%$. Our results were however higher than the reported awareness level of $23.24 \%$ in a survey conducted in Indian population by Chowdhary et al. $^{8}$

Of the patients who had heard of implant treatment before, $42 \%$ (203) also stated that the dental implants will be placed in the jawbone.

\section{Dental Implant as an Option for Replacement of Missing Teeth}

With regard to dental implants as a replacement of missing teeth in Melmaruvathur population, about half of the surveyed patients are totally unaware.

\section{Life Span of Dental Implant Treatment}

A pertinent observation was made when patients were asked about their expectation of the life span of a dental implant, around $20 \%$ of the patients expected the life span to be 20 years and $41 \%$ expected it to last for a lifetime. With highly unrealistic patient expectations, the need for patient education arises.

\section{Need for Special Care and Hygiene}

A total of $54 \%$ of the patients had responded that dental implants needed less postoperative care than natural teeth.

\section{Interested in Knowing and Getting Treated with Dental Implants}

Around $75 \%$ of the dental patients questioned in this survey were interested in knowing more information as well as willing to get treated with dental implants. Breakup analysis shows that this was consistent across all gender, age groups, and occupational and educational status. This outlines the yearning in dental patients for education about implants.

\section{CONCLUSION}

- There is a need for more dental education programs to improve the level of understanding pertaining to the importance of restoration of the missing teeth.

- General awareness levels of implant are satisfactory. However, there is a need for more awareness among patients for restoration of missing teeth with dental implants.

- Dental education programs with special emphasis on advantages, treatment, maintenance, and postoperative care of dental implant therapy are needed.

- More than two-thirds of the surveyed population is interested in knowing and getting treated with dental implants.

\section{REFERENCES}

1. Kohli S, Bhatia S, Kaur A, Rathakrishnan T. Trends in patients' mindset on dental implants: a survey in Malaysia. J Dent Implants 2014 Jan-Jul;4(1):33-35.

2. Pommer B, Zechner W, Watzak G, Ulm C, Watzek G, Tepper G. Progress and trends in patients' mindset on dental implants. I: level of information, sources of information and need for patient information. Clin Oral Implants Res 2011 Feb;22(2): 223-229.

3. Zimmer CM, Zimmer WM, Williams J, Liesener J. Public awareness and acceptance of dental implants. Int J Oral Maxillofac Implants 1992 Summer;7(2):228-232.

4. Berge TI. Public awareness, information sources and evaluation of oral implant treatment in Norway. Clin Oral Implants Res 2000 Oct;11(5):401-408.

5. Tepper G, Haas R, Mailath G, Teller C, Zechner W, Watzak G, Watzek G. Representative marketing-oriented study on implants in the Austrian population. I. Level of information, sources of information and need for patient information. Clin Oral Implants Res 2003 Oct;14(5):621-633.

6. Satpathy A, Porwal A, Bhattacharya A, Sahu PK. Patient awareness, acceptance and perceived cost of dental implants as a treatment modality for replacement of missing teeth: a survey in Bhubaneswar and Cuttack. Int J Public Health Dent 2011 Jan-Jun;2(1):1-7.

7. Ravi Kumar C, Pratap KVNR, Venkateswararao G. Dental implants as an option in replacing missing teeth: a patient awareness survey in Khammam, Andhra Pradesh. Indian J Dent Sci 2011 Dec;5(3):33-37.

8. Chowdhary R, Mankani N, Chandraker NK. Awareness of dental implants as a treatment choice in urban Indian populations. Int J Oral Maxillofac Implants 2010 Mar-Apr;25(2): 305-308.

9. Muller F, Wahl G, Fuhr K. Age-related satisfaction with complete dentures, desire for improvement and attitudes to implant treatment. Gerodontology 1994 Jul;11(1):7-12.

10. Akagawa Y, Rachi Y, Matsumoto T, Tsuru H. Attitudes of removable denture patients toward dental implants. J Prosthet Dent 1988 Sep;60(3):362-364.

11. Saha A, Dutta S, Vijaya V, Rajnikant N. Awareness among patients regarding Implants as a treatment option for replacement of missing teeth in Chattisgarh. J Int Oral Health 2013 Oct;5(5):48-52. 